\title{
The principle of referral: the gatekeeping role of the GP
}

As far as I know, it is only in the UK that the principle of referral has been an accepted custom for as long as 100 years. The principle is simple. Apart from accidents and emergencies and a few 'open-access clinics' such as genitourinary medicine, if patients need to be seen by a hospital doctor they have to be referred by a GP. This often puzzles people from other countries, but it is something the British public takes for granted. The question of when and why the principle was introduced is the subject of this paper.

From the time they were founded in the mid-18th century, the hospitals (which were financed solely by charitable subscribers) admitted both out-patients and in-patients on only one specified day of the week. Injuries from accidents, and obvious emergencies, were admitted at any other time. The rest, mostly patients with medical illnesses, were required to bring a 'passport' in the form of a letter of recommendation from a subscriber to the hospital (although this rule died out in the second half of the 19th century). Thus, the rules of the Radcliffe Infirmary in Oxford (founded in 1770) stated:

\begin{abstract}
'That the Out-Patients be assisted with Advice and Medicines only, and in no other way chargeable to the Infirmary ... that they attend exactly at 11 o'clock ev. Saturday ... and that no fresh medicine be given them, until they deliver their Phials or Gallipots and such medicines as they have not taken."
\end{abstract}

Two points must be made here. First, very few if any of the patients admitted to outpatients or in-patients were referred by GPs. Second, although the industrial revolution was associated with a huge increase in illness, hospitals before the mid-19th century provided a grossly inadequate medical service to the poor for whom they had been founded.

By the 1830s, the number of out-patients seen per year in provincial hospitals (for example, at Oxford, Gloucester, Salisbury, Birmingham or Bristol) was about 20 a week, and in London hospitals slightly more. There is no evidence to suggest that patients were frequently turned away or that hospital care was deliberately rationed.* Therefore, until the mid-19th century, the majority of the poor must have treated themselves, paid a small private fee to a GP, or turned to other charities such as the dispensaries. After the 1840s, however, starting in London and slightly later in the provinces, the trickle of hospital out-patients began to turn into a flood. As we will see, it was a flood of astonishing proportions.

Table 1 shows that at The (Royal) London Hospital the annual number of out-patient attendance was (in round figures) about 1000 in the decade 1800-1809, 17000 in 1850-1859, and 220000 in 1900-1909. Thus by 1900 The London Hospital was seeing, on average, over 4200 out-patients a week or (excluding Sundays) over 700 a day. These patients were seen in the space of 2-3 hours each morning with the average consultation lasting about 1 minute or less, during which they were seen and prescribed a bottle of medicine by junior hospital staff. If there were any 'interesting cases' they were sent up to the wards as 'good teaching material' to be used by the senior honorary (consultant) physicians who only appeared on the wards, never at out-patients.

In 1887, the grand total of out-patient and casualty admissions at all London hospitals, general and special, amounted to 1.29 million. $^{2}$ You might assume that this was largely a London phenomenon but, as the table shows, out-patient numbers increased in most if not all hospitals. Henry Burdett, an authority on nineteenth-century hospitals, calculated the annual number of out-patient attendance in 34 towns in 1892 and expressed them as annual rates per 1000 population. ${ }^{3}$ Unexpectedly, London, where the rate was 274 , did not head the list. Dublin came top with a rate of 489 , followed (in this order) by Liverpool, Edinburgh, Bristol, Leicester, Birmingham, Newcastle,

${ }^{\star}$ The sources of all the statistics mentioned here come from the original records of the hospitals most of which are held in the appropriate County Record Offices.
Manchester, and Brighton - all of which had higher rates than London.

In 1878, well before out-patient numbers had reached their peak, the Secretary of the Westminster Hospital stated it was 'an almost universal opinion that the out-patient departments have grown to such an unruly size as to be almost unmanageable. ${ }^{4} \mathrm{~A}$ large number of reports from charitable foundations, parliament, and many other authorities showed that out-patients was so chaotic that the hospital service was in danger of breaking down. One of the most memorable reports, from which I have selected a few extracts, was written by Robert Bridges (who later became Poet Laureate) about his experience as a casualty physician at St Bartholomew's Hospital. ${ }^{5}$

'Anyone with an eye for figures reading the Clerk's report for St. Bartholomew's Hospital for the year, say 1877, must, if previously unused to such facts, feel his mind somewhat unhinged by the statement that 157947 patients were relieved at that institution in the course of the year. He might cut out the 5000 and odd in-patients, and the 780 women attended at their houses, but he would still be left with a total of 151836 persons who were actually registered as visiting the hospital presumably for the first time, and having their complaints investigated and treated ...'

Bridges added that follow-up attendance were not included in the totals and a sizeable number escaped registration, so that the true total was nearer 200000 than 150000 .

'The surgery [that is, out-patient department] is a large hall, 90 feet by 30 feet with rooms opening off it at the four corners ... One half of the hall, with the rooms off it, is devoted to the women, the other half to men ... The work is done in the mornings and patients are admitted at 9 o'clock [when] the doors are thrown open ... [and] forcibly held ajar by the porters ... This 
goes on until, at 10 o'clock precisely, the doors are forcibly shut. If anyone should go into the hall at about 20 past 9 , he would see some 100 persons standing in an orderly manner ... the women engaged in conversation, the men waiting in silence. If he goes out and comes in again at 11, he will frequently find the room nearly or quite empty.'

Bridges was deeply shocked by having to deal every day with:

'... some 200 paupers, who are many of them seriously ill, some mortally, many but slightly, but nearly all with considerable bodily inconvenience or pain which, unless disease be a joke, and this the whole constitution of our hospital forbids us to suppose, entitles them to his patient attention and investigation, and demands his skill and advice.'

Although his seniors accused Bridges of exaggeration, in 1912 Sir HT Butlin, President of the BMA and President of the Royal College of Surgeons, referred to Bridges report, saying that 'conditions are precisely similar at the present time'. ${ }^{6}$

Senior hospital staff were ambivalent towards the out-patient problem. They could, indeed should have seen that outpatient chaos was incompatible with good medical care, but they firmly believed that the larger the numbers of patients they claimed to have 'treated', the more subscriptions they would attract.

But those who were loudest in their condemnation of this scandalous state of affairs were the GPs. In areas such as the East End of London, until the 1840s GPs earned (or scraped) a living by charging the working classes sixpence or a shilling for a visit to the surgery and sixpence for the inevitable bottle of medicine. Out-patients however was free, and as the number of patients increased GPs were forced to reduce their fees. Many went bankrupt.

By the end of the 19th century it was clear that something had to be done because, as one correspondent put it in 1894: 'The abuse of the hospitals' out-patients departments is an evil so gigantic that the tendency is to regard it as being unavoidable ...' $\mathrm{He}$ recommended that only cases which were

Table 1. The annual average out-patient attendance at three London and three provincial hospitals in each decade between 1800-1809 and 1900-1909.

London hospitals

\begin{tabular}{|c|c|c|c|}
\hline Decade & $\begin{array}{l}\text { The London } \\
\text { Hospital }\end{array}$ & $\begin{array}{c}\text { St Bartholomew's } \\
\text { Hospital }\end{array}$ & $\begin{array}{l}\text { Royal Free } \\
\text { Hospital }\end{array}$ \\
\hline 1800-1809 & 1001 & 4450 & - \\
\hline 1810-1819 & 2597 & - & - \\
\hline $1820-1829$ & 5422 & 7491 & - \\
\hline 1830-1839 & 6256 & 43551 & 3789 \\
\hline 1840-1849 & 11913 & 65747 & 27562 \\
\hline 1850-1859 & 17053 & 84983 & 34019 \\
\hline 1860-1869 & 25906 & 128110 & 66662 \\
\hline 1870-1879 & 52226 & 160520 & $39241^{a}$ \\
\hline 1880-1889 & 80231 & 144681 & 22381 \\
\hline 1890-1899 & 141643 & 165719 & 31229 \\
\hline 1900-1909 & 221780 & 150743 & 38625 \\
\hline \multicolumn{4}{|c|}{ Provincial hospitals } \\
\hline Decade & $\begin{array}{c}\text { Radcliffe } \\
\text { Infirmary Oxford }\end{array}$ & $\begin{array}{l}\text { Gloucester } \\
\text { Infirmary }\end{array}$ & $\begin{array}{c}\text { North Staffordshire } \\
\text { Infirmary }\end{array}$ \\
\hline $1800-1809$ & 296 & 341 & 513 \\
\hline 1810-1819 & 247 & 243 & 855 \\
\hline $1820-1829$ & 258 & 251 & 1451 \\
\hline 1830-1839 & 522 & 500 & 1986 \\
\hline $1840-1849$ & 1348 & 583 & 3113 \\
\hline 1850-1859 & 2893 & 762 & 4519 \\
\hline 1860-1869 & 4633 & 1119 & 4917 \\
\hline 1870-1879 & 4463 & 3714 & 5713 \\
\hline 1880-1889 & 6030 & 5055 & 9213 \\
\hline 1890-1899 & 6931 & 7513 & 10048 \\
\hline 1900-1909 & 8567 & 9010 & - \\
\hline
\end{tabular}

Sources: The annual reports and other archives of each hospital.

aThe apparent fall in out-patient attendance in the 1870s at the Royal Free Hospital was due to a change (from 1865) in the system of recording such attendance

'certified by a medical man as requiring special consideration' should be admitted to out-patients. ${ }^{7}$ Numerous articles took the same view, which also received strong backing from the BMA.

This was the origin of the principle of referral. In the future only patients who had obtained a letter from their GP should be received in out-patients. Although this principle was only accepted slowly over several decades, it received a boost from the introduction of the National Health Insurance Act of 1911. The chaos of outpatients had been largely, though not entirely, due to the fact it was free of any charges. The National Insurance Act provided free care from GPs for the same population that had flooded the out-patient departments - the working classes, for the most part socially above the paupers, but below the middle and upper classes. It was no longer necessary for the poor to fight their way into a hospital for a 1-minute consultation; hence the marked decrease in out-patient attendance after 1913.

Originally the passport to hospital care was the subscriber's letter. It was, for several reasons, a bad system that died out in the mid-19th century. By the early 20th century the passport became the GP's letter. Although the primary reason for introducing the principle of referral or 'the gate keeping role', was the protection of the income of GPs, it has proved to be a sensible and important way of regulating and coordinating primary and secondary medical care.

One obvious question is left hanging in the air. Why did out-patients suddenly become so popular? Why did the flood of out-patient admissions start when it did and rise so 
steeply? It was probably a cultural change associated with changing public attitudes towards orthodox medicine. But in spite of puzzling about it for years I can produce no convincing answers.

\section{Irvine Loudon}

\section{REFERENCES}

1. Archives of the Radcliffe Infirmary, Oxford.

2. Rivington W. The medical profession. Dublin: Fannin and Co., 1879.

3. Burdett H. Hospitals and asylums of the world. London: Churchill, 1893.

4. Archives of Westminister Hospital, London. Annual reports.

5. Bridges R. An account of the Casualty Department. St.
Bartholomew's Hospital Reports, 1878; 14: 167-182.

7. King's Hospital Fund for London. Report of the Committee appointed to inquire into the system prevailing in the London Hospitals with regard to admission to out-patients. London: King's Hospital Fund for London, 1912.

DOI: 10.3399/bjgp08X277113

\section{COMMENTARY}

The theological justification of general practice usually stresses personal continuing care and tri-partite diagnosis. In reality the main scientific basis for having generalists practising in the community is because gatekeeping is an effective way to increase the prevalence of serious disease in the population of patients whom hospital doctors see. Since a high prevalence of disease in a population ensures that the positive predictive value of signs and symptoms is increased, having effective gatekeepers turns out to make the diagnostic task of hospital doctors easier. And by the same token enables GPs to be much better at diagnosing normalcy - 'I don't know what's wrong with you but it isn't serious' is predicated on the fact that an absent sign or symptom has a high negative predictive value in low prevalence populations. Gatekeeping might have started out as a restrictive practice but hey! it was actually us being really cool on behalf of our patients. So everyone's happy and health systems where generalists restrict referrals turn out to be more efficient than those without. ${ }^{1}$

But what about gatekeeping today? Now that we finally understand just how important gatekeeping is for efficient care is that the end of the story? Turns out that we can, and should, be doing much better. Suppose that in your next surgery you see a 50-year-old white woman of BMI 30 with three episodes of vaginal bleeding over the last 15 months. Deciding whether she needs referral would be much easier if we knew the predictive value of this given set of signs and symptoms in this particular population of women when seen in the community.

Such finely-tuned predictive values are within our grasp - indeed, they have been so for several years had we bestirred ourselves. All we need is a significant number of practices to log $100 \%$ of all relevant symptoms and then record $100 \%$ of all relevant diagnoses and outcomes. Plus a great deal of commitment and hard work. At scale and with up to 1 million consultations per day clicking through the counters, this would progressively turn our collective diagnostic skills, intuitions, and failings into a set of evermore refined and wideranging positive and negative predictive values for community-based symptom complexes. Such a system could ultimately provide the consulting clinician with evidence-based statements of probable disease risk that incorporated genetic, demographic, and symptom variables tuned to each individual in front of them. In time it could also incorporate the prior probabilities for diagnostic tests of interest and link particular treatments with actual outcomes.

Would this mean the end of gatekeeping? That depends on whether it would still be useful to have diagnosis carried out in those highprevalence settings that we currently call hospitals. In short, whether it is economically worthwhile to have something on the other side of the gate.

Ironically, and by the back door, we have come full circle to some kind of 'personalised' care. But now 'personal' does not mean what the patient as a person desires but what particular combination of tests and treatments is likely to most benefit this individual collection of demographic, genetic, and symptom complex risks that is currently consulting with me. ${ }^{2}$

Such a vision is an example of how the new informational fabrics that are enveloping our world can be used to link very large scale social networks with massed data into entirely new solutions. In this new world Google constitutes our swaddling clothes, wrapping us in any information we desire. GPS is our baby bouncer, guiding us through an always-mapped universe. The NHS with its 1 million GP consultations a day clocking through the new electronic record (I'm an optimist) constitutes the substrate out of which we could, if we wished, create a medical informational fabric of equal import to Google and GPS. One that provides us with the tools to practice 21 st century medicine in community settings. Or we can sit on our hands and hope that our restrictive practices and current market dominance will keep out the competition for another 100 years.

\section{Paul Hodgkin}

\section{REFERENCES}

1. Mathers NJ, Hodgkin P. The Gatekeeper and the Wizard - a fairytale. BMJ 1989; 298:172-174.

2. Hagel J III, Brown Seely J. The only sustainable edge: why business strategy depends on productive friction and dynamic specialization. Cambridge, MA: Harvard Business School, 2005. 